\title{
Clinical outcomes of radial probe endobronchial ultrasound using a guide sheath for diagnosis of peripheral lung lesions in patients with pulmonary emphysema
}

Kyu Min Lee ${ }^{1 \dagger}$, Geewon Lee ${ }^{2 \dagger}$, Ahreum Kim³, Jeongha Mok', Ji Won Lee², Yeon Joo Jeong ${ }^{2}$, Eun-Jung Jo', Mi Hyun Kim', Kwangha Lee ${ }^{1}$, Ki Uk Kim¹, Hye-Kyung Park', Min Ki Lee ${ }^{1}$ and Jung Seop Eom ${ }^{14^{*}}$ (D)

\begin{abstract}
Background: Generally, structural destruction of lung parenchyma, such as pulmonary emphysema, is considered to be related to the low diagnostic yields and high complication rates of lung biopsies of peripheral lung lesions. Currently, little is known about the clinical outcomes of using endobronchial ultrasound with a guide sheath (EBUS-GS) to diagnose peripheral lesions in patients with emphysema.

Methods: This retrospective study was performed to identify the clinical outcomes of EBUS-GS in patients with pulmonary emphysema. This study included 393 consecutive patients who received EBUS-GS between February 2017 and April 2018. The patients were classified according to the severity of their emphysema, and factors possibly contributing to a successful EBUS-GS procedure were evaluated.

Results: The overall diagnostic yield of EBUS-GS in patients with no or mild emphysema was significantly higher than in those with moderate or severe pulmonary emphysema ( $78 \%$ vs. $61 \%, P=0.007)$. There were no procedurerelated complications. The presence of a bronchus sign on $C T(P<0.001)$ and a "within the lesion" status on EBUS $(P=0.009)$ were independently associated with a successful EBUS-GS procedure. Although the diagnostic yield of EBUS-GS in patients with moderate-to-severe emphysema was relatively low, a bronchus sign and "within the lesion" status on EBUS were contributing factors for a successful EBUS-GS.
\end{abstract}

Conclusions: EBUS-GS is a safe procedure with an acceptable diagnostic yield, even when performed in patients with pulmonary emphysema. The presence of a bronchus sign and "within the lesion" status on EBUS were predictors of a successful procedure.

Keywords: Bronchoscopy, Diagnosis, Lung neoplasms, Pulmonary emphysema, Ultrasound

\footnotetext{
* Correspondence: ejspulm@gmail.com

${ }^{\dagger}$ Kyu Min Lee and Geewon Lee contributed equally to this work.

'Department of Internal Medicine, Pusan National University School of

Medicine, 179 Gudeok-ro, Seo-gu, Busan 602-739, Korea

${ }^{4}$ Biomedical Research Institute, Pusan National University Hospital, Busan,

Republic of Korea

Full list of author information is available at the end of the article
}

(c) The Author(s). 2019 Open Access This article is distributed under the terms of the Creative Commons Attribution 4.0 International License (http://creativecommons.org/licenses/by/4.0/), which permits unrestricted use, distribution, and reproduction in any medium, provided you give appropriate credit to the original author(s) and the source, provide a link to the Creative Commons license, and indicate if changes were made. The Creative Commons Public Domain Dedication waiver (http://creativecommons.org/publicdomain/zero/1.0/) applies to the data made available in this article, unless otherwise stated. 


\section{Background}

Low-dose computed tomography (LDCT) is widely used for lung cancer screening in high-risk individuals such as those with pulmonary fibrosis or chronic obstructive pulmonary disease, and its value for reducing mortality rate was clearly demonstrated in the US National Lung Screening Trial [1]. Although the use of LDCT to screen high-risk populations has resulted in a decrease in lung cancer mortality of $20 \%$ compared with screening using chest radiographs, high false-positive rates and the low prevalence of lung cancer are still considered major limitations to its widespread use $[2,3]$. In this respect, pulmonary physicians and radiologists may find it challenging to distinguish early stage lung cancer from a benign lung nodule on LDCT $[4,5]$.

The National Comprehensive Cancer Network recommends histological examination for patients with a solid nodule greater than $8 \mathrm{~mm}$ on the initial LDCT screen [6]. Lung biopsy for a peripheral lung lesion is traditionally performed using transthoracic needle aspiration, bronchoscopy, or surgical wedge resection [5]. High-risk individuals who receive LDCT screening for lung cancer have a smoking history of more than 30 pack-years [7], and because of the possibility of reduced lung function or advanced lung destruction such as that due to pulmonary emphysema, a less invasive strategy for collecting lung tissue is required [8].

Radial probe endobronchial ultrasound using a guide sheath (EBUS-GS) has been widely used to diagnose peripheral lung lesions, with an acceptable diagnostic yield and a low complication rate [9-11]. Until now, only one previous study has shown that pulmonary emphysema may be a risk factor for pneumothorax after EBUS-GS [12]. Structural destruction of lung parenchyma, such as pulmonary emphysema, is considered to be related to the low diagnostic yields and high complication rates of lung biopsies. At present, the accuracy and safety profile of EBUS-GS in patients with pulmonary emphysema remains unclear. Thus, we used a prospectively collected database to identify the clinical outcomes of EBUS-GS in patients with pulmonary emphysema.

\section{Methods}

\section{Study population}

This retrospective study was performed using an EBUSGS database to investigate the clinical outcomes of EBUS-GS in patients with pulmonary emphysema. The patients were examined between February 2017 and April 2018 at Pusan National University Hospital, a university-affiliated tertiary referral hospital in Busan, Republic of Korea. A total of 393 patients with peripheral lung lesions who received EBUS-GS during the study period were selected for the present study. The Institutional Review Board of Pusan National University
Hospital approved this study, and the requirement for informed consent was waived because of the retrospective nature of the study (no. H-1809-013-071).

\section{CT scan and emphysema severity}

CT scans were obtained in the full-inspiratory state using a commercial CT scanner (Revolution CT; GE Healthcare, Milwaukee, WI, USA). Images of the whole thorax were taken using the following $\mathrm{CT}$ parameters: $120 \mathrm{kVp}$; 100-250 mAs; tube rotation, 0.5 ; and slice thickness, $0.625 \mathrm{~mm}$ with an interval of $0.625 \mathrm{~mm}$. Axial, coronal, and sagittal images were displayed with mediastinal (width, 400 Hounsfield units [HU]; level, $20 \mathrm{HU}$ ) and lung window settings (width, $1500 \mathrm{HU}$; level, -700 $\mathrm{HU})$.

A peripheral lung lesion was defined as an intrapulmonary lesion beyond the segmental bronchus visible on the axial CT scan. The mean diameter of a peripheral lung lesion was defined as the mean of the maximum transverse diameter and its perpendicular diameter on axial images with a lung window setting. As in a previous study, peripheral lung lesions were classified as solid, ground-glass opacity, mixed, or cavitary [13]. Bronchus sign on CT scan was defined as the presence of a bronchus leading directly to a peripheral lung lesion.

Thin-section CT scans were reviewed by an experienced thoracic radiologist. Emphysema was defined as a low-attenuation lung area lacking a distinct wall [14]. The extent of pulmonary emphysema was visually estimated according to a previous guideline [15], and patients were classified into three groups: mild, moderate, and severe emphysema. Briefly, mild emphysema was defined as scattered centrilobular lucencies, usually separated by large regions of normal lung, and involving an estimated $0.5-5 \%$ of a lung zone, or small $(\leq 1 \mathrm{~cm})$ juxtapleural lucencies. Moderate emphysema was defined as many well-defined lucencies occupying more than 5\% of any lung zone. Severe emphysema included confluent centrilobular emphysema, advanced destructive emphysema, and substantial paraseptal emphysema [15].

\section{EBUS-GS procedure}

EBUS-GS was performed using the standard techniques of Kurimoto [9], and all procedures during the study period were performed without any assistance from novel navigation modalities such as electromagnetic navigation bronchoscopy or virtual bronchoscopy $[10,11]$. A representative case of EBUS-GS in a patient with pulmonary emphysema is shown in Fig. 1. Briefly, using a thin-section chest CT scan for guidance, a thin bronchoscope (BFP260F; Olympus, Tokyo, Japan) was advanced as close as possible to the target peripheral lesion under conscious sedation. Then, a $20 \mathrm{MHz}$ radial EBUS probe (UM-S2017S; Olympus), covered with a GS (K-201; Olympus) was 

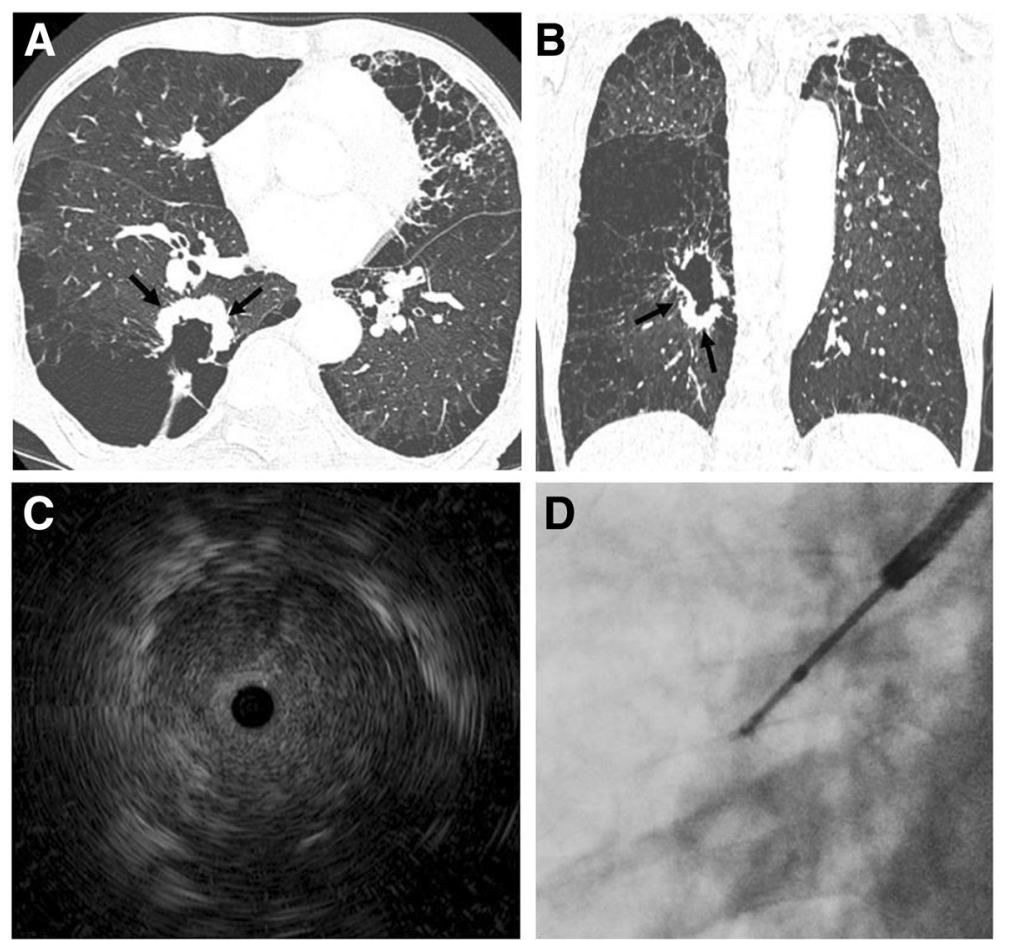

Fig. 1 Representative case of EBUS-GS in a patient with severe pulmonary emphysema. a and $\mathbf{b}$ A $31 \times 37$ mm cavitary lesion in the right lower lobe is shown on axial and coronal computed tomography scans of a patient with severe emphysema. Because of the advanced lung destruction around the tumor (black arrow), it was impossible to perform percutaneous needle aspiration for a histological examination. c Radial probe EBUS shows "within the lesion" status. d A transbronchial lung biopsy was performed under fluoroscopic guidance, and squamous cell carcinoma was diagnosed. EBUS-GS, endobronchial ultrasound using a guide sheath

introduced through the working channel of the bronchoscope to precisely locate the target lung lesion. Following previously reported classifications $[9,16,17]$, radial probe EBUS findings of the target peripheral lesion were classified as within, adjacent to, or outside of the lesion (Fig. 2). After identifying the target lesion on the radial probe EBUS, subsequent brush cytology and forceps biopsy were performed under X-ray fluoroscopic guidance. To prevent infectious complications, prophylactic antibiotics were empirically prescribed for patients with cavitary lesions or structurally damaged lung, according to previous reports $[18,19]$.

\section{Complications related to EBUS-GS}

Any complications that developed after EBUS-GS were evaluated as described in previous studies [18, 19]. Briefly, severe hemorrhage was defined as procedure-related bleeding requiring endotracheal intubation, transfusion, or another invasive procedure for hemostasis. Chest radiographs were performed $4 \mathrm{~h}$ after the procedure and on the
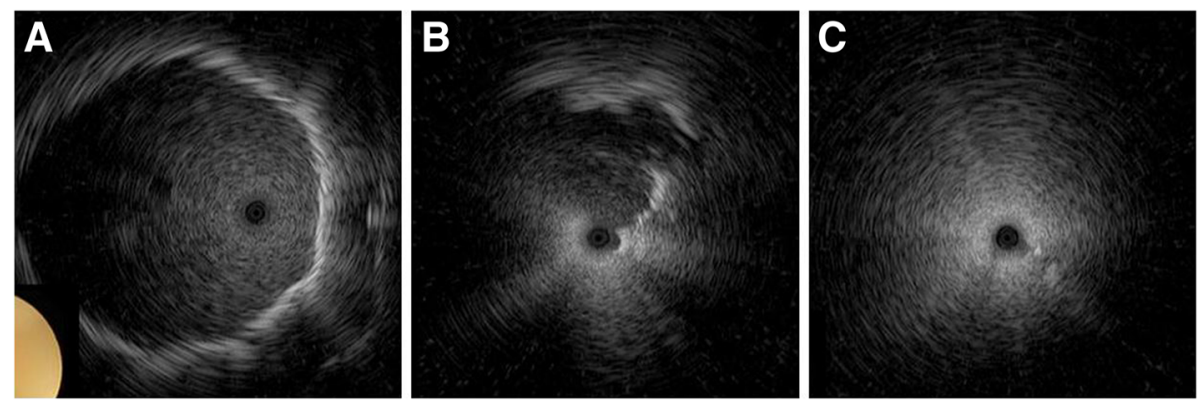

Fig. 2 EBUS image according to the relationship between the peripheral lung lesion and the bronchus. The radial EBUS was positioned inside the peripheral lung lesion (a, within), in the bronchus adjacent to the lung lesion (b, adjacent to) and outside the lung lesion (c, outside). EBUS, endobronchial ultrasound 
following day to check the iatrogenic pneumothorax after EBUS-GS. Infectious complications, air embolisms, respiratory failure, and premature termination of the procedure due to an unexpected complication during EBUS-GS were recorded by the physicians performing the procedures.

\section{Statistical analysis}

All results are presented as median values (interquartile range [IQR]) for continuous variables and as numbers (percentages) for categorical variables, as appropriate. The categorical data were compared using Pearson's chi-square or Fisher's exact test, and the Mann-Whitney $U$ test was used to compare continuous variables. Multivariate logistic regression analysis was used to examine independent factors related to successful EBUS-GS. A $P$-value $<0.1$ was considered significant in the univariate analyses, and $P$-values $<0.05$ were considered significant in all other analyses. SPSS for Windows (ver. 22.0 SPSS Inc., Chicago, IL, USA) was used for the statistical analyses.

\section{Results}

\section{Study population}

Of the 393 study patients who received EBUS-GS, pulmonary emphysema was found in 129 patients (33\%). The baseline characteristics of the patients with and without pulmonary emphysema are shown in Table 1 . The proportion of male gender was higher in study subjects with pulmonary emphysema than in those without emphysema on CT $(98 \%$ vs. $53 \%, P<0.001)$. The median forced expiratory volume in $1 \mathrm{~s}$ and the forced expiratory volume in $1 \mathrm{~s} /$ forced vital capacity ratio were significantly lower in patients with pulmonary emphysema than in those without pulmonary emphysema (79\% predicted value vs. $86 \%$ predicted value, $P<0.001$ for forced expiratory volume in $1 \mathrm{~s} ; 69 \%$ vs. $75 \%, P<0.001$ for forced vital capacity). Otherwise, there were no statistically significant differences in baseline characteristics between patients with and without pulmonary emphysema. The clinical diagnoses of all study patients are presented in Table 2. Of the 129 patients with pulmonary emphysema, mild, moderate, and severe emphysema was found on axial CT in 70 (54\%), 45 (35\%), and 14 (11\%) patients, respectively.

\section{Diagnostic yield}

The diagnostic yields of EBUS-GS in patients with and without pulmonary emphysema were 71 and $77 \%$, respectively, and were not significantly different $(P=$ $0.148)$. In addition, there was no statistically significant difference in the diagnostic yield of EBUS-GS between patients with mild, moderate, or severe pulmonary emphysema $(79,60$, and $64 \%$ for mild, moderate, and severe pulmonary emphysema, respectively, $P=0.089$ ). However, the overall diagnostic yield of EBUS-GS in patients
Table 1 Baseline characteristics of the study patients

\begin{tabular}{|c|c|c|c|}
\hline Variables & $\begin{array}{l}\text { With emphysema } \\
(n=129)\end{array}$ & $\begin{array}{l}\text { Without } \\
\text { emphysema } \\
(n=264)\end{array}$ & $P$-value \\
\hline Age, years & $71(65-76)$ & $69(61-75)$ & 0.064 \\
\hline Male gender & $126(98)$ & $139(53)$ & $<0.001$ \\
\hline Mean diameter of lesion, mm & $28(21-39)$ & $27(19-35)$ & 0.135 \\
\hline Distance from pleura, mm & $1(0-25)$ & $10(0-23)$ & 0.289 \\
\hline \multicolumn{4}{|l|}{ Pulmonary function test ${ }^{\mathrm{a}}$} \\
\hline $\mathrm{FEV}_{1}, \%$ predicted value & $79(66-91)$ & $86(75-97)$ & $<0.001$ \\
\hline FVC, \% predicted value & $82(74-90)$ & $85(75-96)$ & 0.066 \\
\hline $\mathrm{FEV}_{1} / \mathrm{FVC}, \%$ & $69(60-75)$ & $75(70-80)$ & $<0.001$ \\
\hline \multicolumn{4}{|l|}{ Lesion location } \\
\hline Right upper lobe & $36(28)$ & $64(24)$ & 0.525 \\
\hline Right middle lobe & $12(9)$ & $19(7)$ & \\
\hline Right lower lobe & $31(24)$ & $64(24)$ & \\
\hline Left upper division & $22(17)$ & $63(24)$ & \\
\hline Left lingular division & $7(5)$ & $8(3)$ & \\
\hline Left lower lobe & $21(16)$ & $46(17)$ & \\
\hline \multicolumn{4}{|l|}{ Character of lesion on CT scan } \\
\hline Solid & $113(88)$ & $234(89)$ & 0.456 \\
\hline Mixed & $5(4)$ & $16(6)$ & \\
\hline Ground-glass opacity & $2(2)$ & $4(2)$ & \\
\hline Cavitary & $9(7)$ & $10(4)$ & \\
\hline
\end{tabular}

a Pulmonary function test results were available for 245 patients without pulmonary emphysema (93\%)

$I Q R$ interquartile range, $F E V$, forced expiratory volume in $1 \mathrm{~s}, F V C$ forced vital capacity, $C T$ computed tomography

with no or mild emphysema was significantly higher than in those with moderate or severe pulmonary emphysema (78\% for no or mild pulmonary emphysema vs. $61 \%$ for moderate or severe pulmonary emphysema, $P=0.007$; Fig. 3 ).

\section{Factors associated with successful EBUS-GS in patients with emphysema}

Factors affecting the diagnostic yield of EBUS-GS in patients with pulmonary emphysema are compared in Table 3. Univariate analysis revealed that, in comparison with those who did not have a successful EBUS-GS, those patients who had a successful EBUS-GS were more likely to have a lung lesion with a large mean diameter ( $29 \mathrm{~mm}$ vs. $23 \mathrm{~mm}, P=0.008$ ), a greater proportion of mild pulmonary emphysema $(60 \%$ vs. $40 \%$, $P=0.029)$, the presence of a bronchus sign on CT scan (96\% vs. $40 \%, P<0.001$ ), and "within the lesion" status on radial probe EBUS ( $96 \%$ vs. $50 \%, P<0.001)$. Multivariate logistic regression analysis, which was performed to verify the independent factors associated with successful EBUS-GS, showed that the presence of a positive bronchus sign (odds ratio, 33.426; 95\% confidence 
Table 2 Clinical diagnoses of all the patients who underwent EBUS-GS

\begin{tabular}{|c|c|}
\hline Variables & No. (\%) \\
\hline \multicolumn{2}{|c|}{ Patients with pulmonary emphysema } \\
\hline \multicolumn{2}{|l|}{ Diagnosed by EBUS-GS $(n=91)$} \\
\hline Lung cancer & $85(93)$ \\
\hline Pulmonary tuberculosis & $4(4)$ \\
\hline NTM lung disease & $1(1)$ \\
\hline Organizing pneumonia & $1(1)$ \\
\hline \multicolumn{2}{|l|}{ Undiagnosed on EBUS-GS $(n=38)$} \\
\hline Lung cancer & $19(50)$ \\
\hline Pneumonia & $3(8)$ \\
\hline Pulmonary tuberculosis & $1(3)$ \\
\hline Lymphoma & $1(3)$ \\
\hline Unknown & $14(37)$ \\
\hline \multicolumn{2}{|c|}{ Patients without pulmonary emphysema } \\
\hline \multicolumn{2}{|l|}{ Diagnosed by EBUS-GS $(n=204)$} \\
\hline Lung cancer & $187(91)$ \\
\hline Pulmonary tuberculosis & $7(3)$ \\
\hline Pneumonia or lung abscess & $3(2)$ \\
\hline Metastatic lung nodules & $3(2)$ \\
\hline Sarcoidosis & $1(1)$ \\
\hline Fungal infection & $1(1)$ \\
\hline NTM lung disease & $1(1)$ \\
\hline Lymphoma & $1(1)$ \\
\hline \multicolumn{2}{|l|}{ Undiagnosed on EBUS-GS $(n=60)$} \\
\hline Lung cancer & $23(38)$ \\
\hline Metastatic lung nodules & $3(5)$ \\
\hline Fungal infection & $2(3)$ \\
\hline Pneumonia or lung abscess & $2(3)$ \\
\hline Pulmonary tuberculosis & $1(2)$ \\
\hline NTM lung disease & $1(2)$ \\
\hline Interstitial lung disease & $1(2)$ \\
\hline Unknown & $27(45)$ \\
\hline
\end{tabular}

EBUS-GS endobronchial ultrasound using a guide sheath, NTM nontuberculous mycobacteria

interval, 7.550-147.993; $P<0.001)$ and "within the lesion" status on radial probe EBUS (odds ratio, 7.641; 95\% confidence interval, 1.662-35.129; $P=0.009$ ) were independently associated with a successful EBUS-GS in patients with pulmonary emphysema (Table 4).

Table 5 shows how the lesion characteristics were related to the severity of pulmonary emphysema. A bronchus sign was significantly more frequent in patients with mild pulmonary emphysema than in those with moderate-to-severe pulmonary emphysema (89\% vs. $68 \%, P=0.004)$, and patients with mild pulmonary

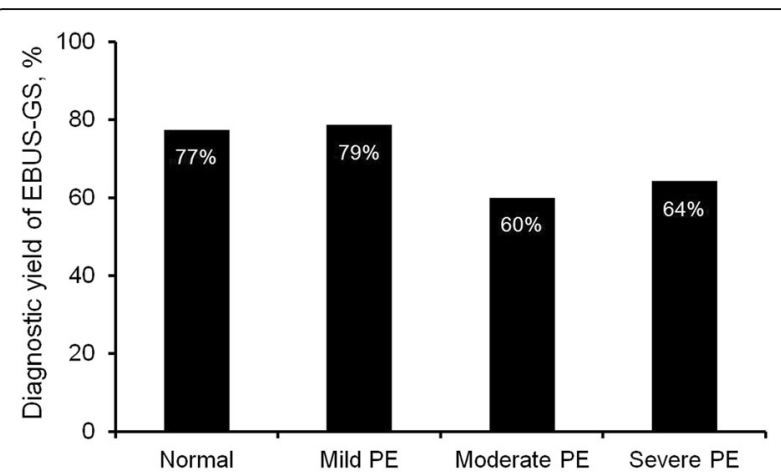

Fig. 3 Diagnostic yield of EBUS-GS according to the severity of emphysema on CT scan. EBUS-GS, endobronchial ultrasound using a guide sheath; $P E$, pulmonary emphysema

emphysema were significantly more likely to show "within the lesion" status on radial probe EBUS than those with moderate-to-severe pulmonary emphysema ( $90 \%$ vs. $73 \%, P=0.011$ ). Otherwise, there were no significant differences between the two groups, including the mean lesion diameter, the distance from the pleura to the lung lesion, and the characteristics of the lesion on CT. An additional multivariate logistic regression analysis was conducted to identify factors predicting successful EBUS-GS in patients with moderate-to-severe pulmonary emphysema (See Additional file 1: Table S1). The bronchus sign on CT scan (odds ratio, 23.459; 95\% CI, 3.464-158.868; $P=0.001$ ) and "within the lesion" status on radial probe EBUS (odds ratio, 10.512; 95\% CI, 1.363-81.047; $P=0.024$ ) were independently associated with a successful EBUS-GS in patients with moderateto-severe pulmonary emphysema.

\section{Complications}

No mortalities or life-threatening complications were associated with the procedure during the study period. None of the patients with pulmonary emphysema developed a pneumothorax, severe hemorrhage, air embolism, or pulmonary infection.

\section{Discussion}

In general, the incidence rate of pneumothorax of any type after percutaneous lung biopsy is $15 \%$ [5], and the presence of pulmonary emphysema is particularly closely associated with pneumothorax after percutaneous lung biopsy [20]. The destruction of lung parenchyma and poor lung function in patients with pulmonary emphysema renders percutaneous lung biopsy difficult. By contrast, guided bronchoscopy such as EBUS-GS has a low complication rate with an acceptable diagnostic yield $[18,21,22]$. A previous study reported that the overall complication rate, including iatrogenic pneumothorax, is 
Table 3 Factors possibly affecting the diagnostic yield of EBUSGS in patients with pulmonary emphysema

\begin{tabular}{|c|c|c|c|}
\hline Variables & $\begin{array}{l}\text { Success } \\
(n=91)\end{array}$ & $\begin{array}{l}\text { Failure } \\
(n=38)\end{array}$ & $P$-value \\
\hline Age, years & $72(64-76)$ & $70(65-75)$ & 0.351 \\
\hline Male gender & $88(97)$ & $38(100)$ & 0.555 \\
\hline $\begin{array}{l}\text { Mean diameter of the lung } \\
\text { lesion, } \mathrm{mm}\end{array}$ & $29(23-39)$ & $23(17-37)$ & 0.008 \\
\hline \multicolumn{4}{|l|}{ Severity of pulmonary emphysema } \\
\hline Mild & $55(60)$ & $15(40)$ & 0.029 \\
\hline Moderate or severe & $36(40)$ & $23(60)$ & \\
\hline $\begin{array}{l}\text { Distance from pleura to lung } \\
\text { lesion, } \mathrm{mm}\end{array}$ & $8(0-27)$ & $0(0-23)$ & 0.231 \\
\hline \multicolumn{4}{|l|}{ Pulmonary function test } \\
\hline $\mathrm{FEV}_{1}, \%$ predicted value & $80(64-89)$ & $77(70-92)$ & 0.953 \\
\hline FVC, \% predicted value & $81(74-89)$ & $84(73-91)$ & 0.468 \\
\hline $\mathrm{FEV}_{1} / \mathrm{FVC}, \%$ & $69(60-75)$ & $67(60-75)$ & 0.614 \\
\hline \multicolumn{4}{|l|}{ Lesion location } \\
\hline Right upper lobe & $27(30)$ & $9(24)$ & 0.570 \\
\hline Right middle lobe & $9(10)$ & $3(8)$ & \\
\hline Right lower lobe & $23(25)$ & $8(21)$ & \\
\hline Left upper division & $16(18)$ & $6(16)$ & \\
\hline Left lingular division & $3(3)$ & $4(11)$ & \\
\hline Left lower lobe & $13(14)$ & $8(21)$ & \\
\hline \multicolumn{4}{|l|}{ Bronchus sign } \\
\hline Positive & $87(96)$ & $15(40)$ & $<0.001$ \\
\hline Negative & $4(4)$ & $23(60)$ & \\
\hline \multicolumn{4}{|l|}{ Character of lesion on $\mathrm{CT}$} \\
\hline Solid & $81(89)$ & $35(92)$ & 1.000 \\
\hline Mixed & $1(1)$ & $0(0)$ & \\
\hline Ground-glass opacity & $1(1)$ & $0(0)$ & \\
\hline Cavitary & $8(9)$ & $3(8)$ & \\
\hline \multicolumn{4}{|l|}{ EBUS finding } \\
\hline Within lesion & $87(96)$ & $19(50)$ & $<0.001$ \\
\hline Adjacent to or outside lesion & $4(4)$ & $19(50)$ & \\
\hline
\end{tabular}

EBUS-GS endobronchial ultrasound using a guide sheath, $F E V_{1}$ forced expiratory volume in $1 \mathrm{~s}$, FVC forced vital capacity, CT computed tomography
$1.3 \%$ [18]; however, we are not aware of any previous study investigating the diagnostic yield or safety profile of EBUS-GS in patients with pulmonary emphysema. In the present study, the overall diagnostic yield of EBUSGS for peripheral lung lesions in the 129 patients with pulmonary emphysema was $71 \%$, without any complications occurring. Many physicians hesitate to make pathologic diagnoses of peripheral lung lesions in patients with pulmonary emphysema because of its associated complications and low diagnostic yields; however, our results suggest that a pathological diagnosis of a peripheral lung lesion can be made safely using EBUS-GS.

Previous studies have reported that the position of the radial EBUS probe during the procedure, lesion size, malignant status, and the bronchus sign on CT contribute to successful EBUS-GS [9, 16, 23, 24]. Similarly, in the present study, a positive bronchus sign on CT and "within the lesion" status on radial probe EBUS were significantly associated with successful EBUS-GS in patients with pulmonary emphysema. Both the EBUS findings and bronchus sign on CT represent the relationship between the target lung lesion and the peripheral bronchus [25]. Our results suggest that the relationship between the peripheral lesion and the bronchus is an important factor, even if EBUS-GS is performed in patients with pulmonary emphysema.

The diagnostic yield of EBUS-GS in patients with mild pulmonary emphysema was similar to that in those without emphysema. Moreover, we found that the diagnostic yield in patients with moderate-to-severe emphysema was significantly lower than that in patients with no or mild pulmonary emphysema. Emphysema is characterized by the destruction of lung parenchyma and alveolar attachment [26]. In general, detection of the bronchus sign in a patient with advanced pulmonary emphysema is difficult because of the destruction of the lung parenchyma. Even if a reconstructed thin-section CT is prepared for EBUS-GS, it is often impossible to differentiate an emphysematous change from the peripheral bronchus on CT. Moreover, narrow and obliterated small airway lumens in patients with moderate-to-severe pulmonary emphysema may contribute to the clinical outcomes of EBUS-GS [27]. However, our results indicate that a clear indication of the bronchus sign on CT scan and "within

Table 4 Multivariate logistic regression analysis to identify independent factors associated with successful EBUS-GS

\begin{tabular}{lll}
\hline & Odds ratio (95\% confidence interval) & $P$-value \\
\hline Age (per year) & $0.958(0.900-1.020)$ & 0.181 \\
Mean diameter of lung lesion (per mm) & $0.993(0.956-1.031)$ & 0.712 \\
Mild pulmonary emphysema & $1.001(0.328-3.053)$ & 0.998 \\
Positive bronchus sign & $33.426(7.550-147.993)$ & $<0.001$ \\
"Within the lesion" EBUS finding & $7.641(1.662-35.129)$ & 0.009 \\
\hline
\end{tabular}


Table 5 Comparisons of EBUS-GS and other characteristics according to the severity of pulmonary emphysema

\begin{tabular}{|c|c|c|c|}
\hline Variables & Mild emphysema $(n=70)$ & $\begin{array}{l}\text { Moderate-to-severe emphysema } \\
(n=59)\end{array}$ & $P$-value \\
\hline Mean diameter of lesion, $\mathrm{mm}$ & $27(22-39)$ & $28(19-39)$ & 0.709 \\
\hline Distance from pleura to lung lesion, $\mathrm{mm}$ & $3(0-22)$ & $0(0-27)$ & 0.927 \\
\hline Number of brushing cytology tests & $3(3-3)$ & $3(2-3)$ & 0.371 \\
\hline Number of biopsies & $6(6-6)$ & $6(6-7)$ & 0.379 \\
\hline \multicolumn{4}{|l|}{ Lesion location } \\
\hline Right upper lobe & $25(36)$ & $11(19)$ & \multirow[t]{6}{*}{0.072} \\
\hline Right middle lobe & $4(6)$ & $8(14)$ & \\
\hline Right lower lobe & $16(23)$ & $15(25)$ & \\
\hline Left upper division & $12(17)$ & $10(17)$ & \\
\hline Left lingular division & $1(1)$ & $6(10)$ & \\
\hline Left lower lobe & $12(17)$ & $9(15)$ & \\
\hline \multicolumn{4}{|l|}{ Bronchus sign } \\
\hline Positive & $62(89)$ & $40(68)$ & \multirow[t]{2}{*}{0.004} \\
\hline Negative & $8(11)$ & $19(32)$ & \\
\hline \multicolumn{4}{|l|}{ Character of lesion on $\mathrm{CT}$} \\
\hline Solid & $62(89)$ & $54(92)$ & \multirow[t]{4}{*}{0.484} \\
\hline Mixed & $0(0)$ & $1(2)$ & \\
\hline $\begin{array}{l}\text { Ground-glass } \\
\text { opacity }\end{array}$ & $1(1)$ & $0(0)$ & \\
\hline Cavitary & $7(10)$ & $4(7)$ & \\
\hline \multicolumn{4}{|l|}{ EBUS finding } \\
\hline Within lesion & $63(90)$ & $43(73)$ & \multirow[t]{2}{*}{0.011} \\
\hline Adjacent to or outside lesion & $7(10)$ & $16(27)$ & \\
\hline
\end{tabular}

FEV ${ }_{1}$ forced expiratory volume in $1 \mathrm{~s}, F V C$ forced vital capacity, EBUS endobronchial ultrasound, CT computed tomography

the lesion" status on EBUS are related to a successful diagnosis of EBUS-GS. Although the diagnostic yield of EBUS-GS in patients with moderate-to-severe pulmonary emphysema was relatively low, the careful selection of patients according to the bronchus sign on CT could lead to a high rate of successful procedures.

EBUS-GS is generally considered to be a safe procedure in comparison with surgical biopsy and percutaneous lung biopsy [5]. Hayama et al. reported an overall complication rate of $1.3 \%$ for EBUS-GS performed on 965 peripheral lung lesions (pneumothorax, 0.8\%; pulmonary infection, 0.5\%) [18], while Huang et al. reported that the incidence of pneumothorax after EBUS-GS was $3.3 \%$ in 399 patients with peripheral lung lesions [12]. However, there were no procedure-related EBUS-GS complications in the present study. In the entire study population with pulmonary emphysema, fluoroscopy was used for the forceps biopsy and brushing cytology through a guide sheath, after precise localization of the peripheral lung lesion with the radial probe EBUS. During EBUS-GS, fluoroscopy helps prevent the forceps or brush from moving out of the exact target location in the peripheral lung lesion. Our results suggest that fluoroscopic guidance could help avoid an iatrogenic pneumothorax, even if EBUS-GS is performed in patients with pulmonary emphysema. Moreover, in the present study, prophylactic antibiotics were prescribed to prevent pulmonary infection in high-risk patients, such as those with a cavitary lesion or a structurally damaged lung. Our results suggest that prophylactic antibiotics in high-risk patients can help prevent infectious complications of EBUS-GS, especially in patients with pulmonary emphysema.

Some limitations of this study should be acknowledged. First, this retrospective study was conducted at a single institution, and there is the potential that selection bias could have influenced our results; therefore, it is difficult to generalize the findings. Second, the number of enrolled patients was relatively small. In particular, the EBUS-GS complication rate may have been underestimated because of the small study population. Third, all EBUS-GSprocedures were performed without the assistance of a navigation system, such as electromagnetic navigation bronchoscopy or virtual bronchoscopy $[10,11]$. To verify our results, a prospective study including a large number of patients with pulmonary emphysema is needed. 


\section{Conclusions}

EBUS-GS was shown to be a safe procedure with an acceptable diagnostic yield, even when performed in patients with pulmonary emphysema. The presence of a bronchus sign and "within the lesion" status on radial probe EBUS were useful predictors for a successful diagnosis.

\section{Additional file}

Additional file 1: Table S1. The affecting factors for diagnostic yield of EBUS-GS in moderate-to-severe pulmonary emphysema. (DOCX $17 \mathrm{~kb}$ )

\section{Abbreviations}

CT: Computed tomography; EBUS: Endobronchial ultrasound; EBUSGS: Endobronchial ultrasound using a guide sheath; HU: Hounsfield units; IQR: Interquartile range; LDCT: Low dose computed tomography; NTM: Nontuberculous mycobacteria

\section{Acknowledgements}

Not applicable.

\section{Authors' contributions}

$\mathrm{KML}, \mathrm{GL}$ and JSE are the guarantors and take responsibility for the content of this manuscript, including the data and analysis. JSE conceived the initial idea and the study design. KML, GL, AK, JM, JWL, YJJ, EJJ, MHK, KL, KUK, HKP, MKL and JSE linked the data, contributed to data analysis and interpreted results. KML, GL, AK, JM, JWL, YJJ, EJJ, MHK, KL, KUK, HKP, MKL and JSE draft the manuscript and all authors revised manuscript and approved the final manuscript.

\section{Funding}

This research did not receive any specific grant from a funding agency in the public, commercial, or not-for-profit sectors.

\section{Availability of data and materials}

Please contact author for data requests.

\section{Ethics approval and consent to participate}

The Institutional Review Board of Pusan National University Hospital approved this study, and the requirement for informed consent was waived because of the retrospective nature of the study (no. H-1809-013-071).

\section{Consent for publication}

Not applicable.

\section{Competing interests}

The authors declare that they have no competing interests.

\section{Author details}

'Department of Internal Medicine, Pusan National University School of Medicine, 179 Gudeok-ro, Seo-gu, Busan 602-739, Korea. ${ }^{2}$ Department of Radiology, Pusan National University School of Medicine, Busan, Republic of Korea. ${ }^{3}$ Biostatistics Team of Regional Center for Respiratory Diseases, Pusan National University Hospital, Busan, Republic of Korea. ${ }^{4}$ Biomedical Research Institute, Pusan National University Hospital, Busan, Republic of Korea.

Received: 29 April 2019 Accepted: 31 July 2019

Published online: 06 August 2019

\section{References}

1. National Lung Screening Trial Research Team, Aberle DR, Adams AM, Berg CD, Black WC, Clapp JD, Fagerstrom RM, Gareen IF, Gatsonis C, Marcus PM Sicks JD. Reduced lung-cancer mortality with low-dose computed tomographic screening. N Engl J Med. 2011;365:395-409.

2. Hasan N, Kumar R, Kavuru MS. Lung cancer screening beyond low-dose computed tomography: the role of novel biomarkers. Lung. 2014;192: 639-48.
3. Nanavaty P, Alvarez MS, Alberts WM. Lung cancer screening: advantages, controversies, and applications. Cancer Control. 2014;21:9-14.

4. Pinsky PF, Gierada DS, Black W, Munden R, Nath H, Aberle D, Kazerooni E. Performance of lung-RADS in the National Lung Screening Trial: a retrospective assessment. Ann Intern Med. 2015;162:485-91.

5. Gould MK, Donington J, Lynch WR, Mazzone PJ, Midthun DE, Naidich DP, Wiener RS. Evaluation of individuals with pulmonary nodules: when is it lung cancer? Diagnosis and management of lung cancer, 3rd ed: American College of Chest Physicians evidence-based clinical practice guidelines. Chest. 2013;143:e93S-120S.

6. National Comprehensive Cancer Network. NCCN Clinical Practical Guidelines in Oncology (NCCN Guidelines) - Lung Cancer Screening. Version 2.2019. https://www.nccn.org/professionals/physician_gls/pdf/lung_screening.pdf. Accessed 15 Nov 2018.

7. National Lung Screening Trial Research Team, Church TR, Black WC, Aberle DR, Berg CD, Clingan KL, Duan F, Fagerstrom RM, Gareen IF, Gierada DS, Jones GC, Mahon I, Marcus PM, Sicks JD, Jain A, Baum S. Results of initial low-dose computed tomographic screening for lung cancer. N Engl J Med. 2013;368:1980-91.

8. Rivera MP, Mehta AC, Wahidi MM. Establishing the diagnosis of lung cancer: diagnosis and management of lung cancer, 3rd ed: American College of Chest Physicians evidence-based clinical practice guidelines. Chest. 2013; 143:e142S-65S.

9. Kurimoto N, Miyazawa T, Okimasa S, Maeda A, Oiwa H, Miyazu Y, Murayama M. Endobronchial ultrasonography using a guide sheath increases the ability to diagnose peripheral pulmonary lesions endoscopically. Chest. 2004;126:959-65.

10. Ishida T, Asano F, Yamazaki K, Shinagawa N, Oizumi S, Moriya H, Munakata M, Nishimura M, Virtual Navigation in Japan Trial Group. Virtual bronchoscopic navigation combined with endobronchial ultrasound to diagnose small peripheral pulmonary lesions: a randomised trial. Thorax. 2011;66:1072-7.

11. Eberhardt R, Anantham D, Ernst A, Feller-Kopman D, Herth F. Multimodality bronchoscopic diagnosis of peripheral lung lesions: a randomized controlled trial. Am J Respir Crit Care Med. 2007;176:36-41.

12. Huang CT, Ruan SY, Liao WY, Kuo YW, Lin CY, Tsai YJ, Ho CC, Yu CJ. Risk factors of pneumothorax after endobronchial ultrasound-guided transbronchial biopsy for peripheral lung lesions. PLoS One. 2012;7:e49125.

13. Takamochi K, Nagai K, Yoshida J, Suzuki K, Ohde Y, Nishimura M, Sasaki S, Nishiwaki Y. Pathologic NO status in pulmonary adenocarcinoma is predictable by combining serum carcinoembryonic antigen level and computed tomographic findings. J Thorac Cardiovasc Surg. 2001;122:325-30.

14. Hansell DM, Bankier AA, MacMahon H, McLoud TC, Muller NL, Remy J. Fleischner society: glossary of terms for thoracic imaging. Radiology. 2008; 246:697-722.

15. Lynch DA, Austin JH, Hogg JC, Grenier PA, Kauczor HU, Bankier AA, Barr RG, Colby TV, Galvin JR, Gevenois PA, Coxson HO, Hoffman EA, Newell JD Jr, Pistolesi M, Silverman EK, Crapo JD. CT-definable subtypes of chronic obstructive pulmonary disease: a statement of the Fleischner society. Radiology. 2015;277:192-205.

16. Yamada N, Yamazaki K, Kurimoto N, Asahina H, Kikuchi E, Shinagawa N, Oizumi S, Nishimura M. Factors related to diagnostic yield of transbronchial biopsy using endobronchial ultrasonography with a guide sheath in small peripheral pulmonary lesions. Chest. 2007;132:603-8.

17. Shirakawa T, Imamura F, Hamamoto J, Honda I, Fukushima K, Sugimoto M, Shirkakusa T. Usefulness of endobronchial ultrasonography for transbronchial lung biopsies of peripheral lung lesions. Respiration. 2004;71:260-8.

18. Hayama M, Izumo T, Matsumoto Y, Chavez C, Tsuchida T, Sasada S. Complications with endobronchial ultrasound with a guide sheath for the diagnosis of peripheral pulmonary lesions. Respiration. 2015;90:129-35.

19. Eom JS, Mok JH, Kim I, Lee MK, Lee G, Park H, Lee JW, Jeong YJ, Kim WY, Jo EJ, Kim MH, Lee K, Kim KU, Park HK. Radial probe endobronchial ultrasound using a guide sheath for peripheral lung lesions in beginners. BMC Pulm Med. 2018;18:137.

20. Lendeckel D, Kromrey ML, Ittermann T, Schafer S, Mensel B, Kuhn JP. Pulmonary emphysema is a predictor of pneumothorax after CT-guided transthoracic pulmonary biopsies of pulmonary nodules. PLoS One. 2017;12: e0178078.

21. Steinfort DP, Khor YH, Manser RL, Irving LB. Radial probe endobronchial ultrasound for the diagnosis of peripheral lung cancer: systematic review and meta-analysis. Eur Respir J. 2011;37:902-10. 
22. Wang Memoli JS, Nietert PJ, Silvestri GA. Meta-analysis of guided bronchoscopy for the evaluation of the pulmonary nodule. Chest. 2012;142: 385-93.

23. Huang $C T$, Ho CC, Tsai YJ, Yu CJ, Yang PC. Factors influencing visibility and diagnostic yield of transbronchial biopsy using endobronchial ultrasound in peripheral pulmonary lesions. Respirology. 2009;14:859-64.

24. Gaeta M, Pandolfo I, Volta S, Russi EG, Bartiromo G, Girone G, La Spada F, Barone M, Casablanca G, Minutoli A. Bronchus sign on CT in peripheral carcinoma of the lung: value in predicting results of transbronchial biopsy. AJR Am J Roentgenol. 1991;157:1181-5.

25. Minezawa T, Okamura T, Yatsuya H, Yamamoto N, Morikawa S, Yamaguchi T, Morishita M, Niwa Y, Takeyama T, Mieno Y, Hoshino T, Uozu S, Goto Y, Hayashi M, Isogai S, Matsuo M, Nakanishi T, Hashimoto N, Okazawa M, Imaizumi K. Bronchus sign on thin-section computed tomography is a powerful predictive factor for successful transbronchial biopsy using endobronchial ultrasound with a guide sheath for small peripheral lung lesions: a retrospective observational study. BMC Med Imaging. 2015;15:21.

26. Baraldo S, Turato G, Saetta M. Pathophysiology of the small airways in chronic obstructive pulmonary disease. Respiration. 2012;84:89-97.

27. Burgel PR, Bourdin A, Chanez P, Chabot F, Chaouat A, Chinet T, de Blic J, Devillier P, Deschildre A, Didier A, Garcia G, Jebrak G, Laurent F, Morel H, Perez T, Pilette C, Roche N, Tillie-Leblond I, Verbanck S, Dusser D. Update on the roles of distal airways in COPD. Eur Respir Rev. 2011;20:7-22.

\section{Publisher's Note}

Springer Nature remains neutral with regard to jurisdictional claims in published maps and institutional affiliations.

Ready to submit your research? Choose BMC and benefit from:

- fast, convenient online submission

- thorough peer review by experienced researchers in your field

- rapid publication on acceptance

- support for research data, including large and complex data types

- gold Open Access which fosters wider collaboration and increased citations

- maximum visibility for your research: over $100 \mathrm{M}$ website views per year

At BMC, research is always in progress.

Learn more biomedcentral.com/submissions 